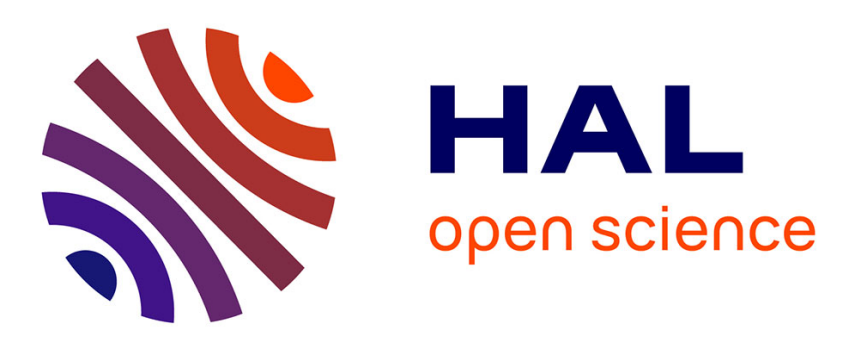

\title{
The Trityl-Cation Mediated Phosphine Oxides Reduction
}

\author{
Claire Laye, Jonathan Lusseau, Frederic Robert, Yannick Landais
}

\section{To cite this version:}

Claire Laye, Jonathan Lusseau, Frederic Robert, Yannick Landais. The Trityl-Cation Mediated Phosphine Oxides Reduction. Advanced Synthesis and Catalysis, 2021, 363 (12), pp.3035-3043. 10.1002/adsc.202100189 . hal-03366257

\section{HAL Id: hal-03366257 https://hal.science/hal-03366257}

Submitted on 5 Oct 2021

HAL is a multi-disciplinary open access archive for the deposit and dissemination of scientific research documents, whether they are published or not. The documents may come from teaching and research institutions in France or abroad, or from public or private research centers.
L'archive ouverte pluridisciplinaire HAL, est destinée au dépôt et à la diffusion de documents scientifiques de niveau recherche, publiés ou non, émanant des établissements d'enseignement et de recherche français ou étrangers, des laboratoires publics ou privés. 


\title{
The Trityl-Cation Mediated Phosphine Oxides Reduction
}

\author{
Claire Laye, ${ }^{\mathrm{a}}$ Jonathan Lusseau, ${ }^{\mathrm{a}}$ Frédéric Robert ${ }^{\mathrm{a} *}$ and Yannick Landais ${ }^{\mathrm{a} *}$
}

a Univ. Bordeaux, CNRS, Institut des Sciences Moléculaires (ISM), UMR-5255, F-33400, Talence, France

phone: (+33)-5 400022 89; e-mail: yannick.landais@u-bordeaux.fr or frederic.robert@u-bordeaux.fr

\begin{abstract}
Reduction of phosphine oxides into the corresponding phosphines using $\mathrm{PhSiH}_{3}$ as a reducing agent and $\mathrm{Ph}_{3} \mathrm{C}^{+}\left[\mathrm{B}\left(\mathrm{C}_{6} \mathrm{~F}_{5}\right)_{4}\right]^{-}$as an initiator is described. The process is highly efficient, reducing a broad range of secondary and tertiary alkyl and arylphosphines, bearing various functional groups in generally good yields. The reaction is believed to proceed through the generation of a silyl cation, which reaction with the phosphine oxide provides a phosphonium salt, further reduced by the silane to afford the desired phosphine along with siloxanes.
\end{abstract}

Keywords: phosphine; reduction; silane; trityl salts; silyl cation.

\section{Introduction}

Phosphines exhibit a wide range of applications in organic and organometallic chemistry. ${ }^{[1]}$ Phosphines are for instance particularly useful as ligands for transition metals. ${ }^{[2]}$ The easy tuning of their steric and electronic properties is one of the key features and allows to modify the reactivity of the metal complex and achieve processes with high turn-over. They have also recently experienced a renewed interest in organocatalysis, ${ }^{[3]}$ for instance in RauhutCurrier reactions. Phosphines are used in key industrial processes such as the Wittig reaction for the synthesis of vitamin ${ }^{[4 \mathrm{a}]}$ but also in Mitsunobu ${ }^{[4 \mathrm{~b}]}$ and Appel ${ }^{[4 \mathrm{c}]}$ reactions leading to the corresponding phosphine oxides as byproducts. The major representative, i.e. triphenylphosphine, thus leads each year to thousands of tons of triphenylphosphine oxide which must be disposed. Recycling wastes into valuable chemicals has become a central issue in chemical industry who wish to fulfill most of the green chemistry principles ${ }^{[5 a]}$ and circular economy. ${ }^{[5 b]}$ Phosphines, and most notably alkylphosphines are easily oxidized into the corresponding phosphine oxides and their reduction back to the trivalent phosphorus compound is particularly difficult due to the strong $\mathrm{P}=\mathrm{O}$ bond (120 kcal.mol $\left.{ }^{-1}\right) \cdot{ }^{[6]} \mathrm{A}$ large variety of reagents are able to reduce phosphine oxides, ${ }^{[7]}$ including aluminium hydrides, ${ }^{[8]}$ boranes, ${ }^{[9]} \mathrm{Cp}_{2} \mathrm{TiCl}_{2}$ in the presence of magnesium, ${ }^{[10]} \mathrm{CaH}_{2},{ }^{[11]}$ Schwartz reagent $\left(\mathrm{Cp}_{2} \mathrm{ZrHCl}_{\mathrm{n}}{ }^{[12]}\right.$ and $\mathrm{SmI}_{2} .{ }^{[13]}$ However, these highly reactive compounds, often require harsh conditions and/or long reaction times, which are not always compatible with a wide array of functional groups. Hydrosilanes have gained importance as reducers as they are nontoxic, commercially available, relatively inexpensive and possess a satisfying reactivity under mild conditions. ${ }^{[7,14,15]}$ Their structure may be modulated as required, varying the number of hydrogens attached to the silicon and their steric and electronic nature easily tuned. $\mathrm{Cl}_{3} \mathrm{SiH}, \mathrm{PhSiH}_{3}, \mathrm{Ph}_{2} \mathrm{SiH}_{2},(\mathrm{EtO})_{3} \mathrm{SiH}, \mathrm{Ph}_{3} \mathrm{SiH}$ or $\mathrm{PMHS}$ (polymethylhydrosiloxane), and more recently the cheap TMDS (tetramethyldisiloxane) ${ }^{[16]}$ have been used for this purpose.

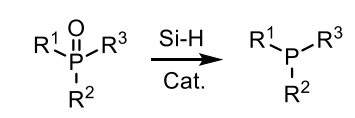

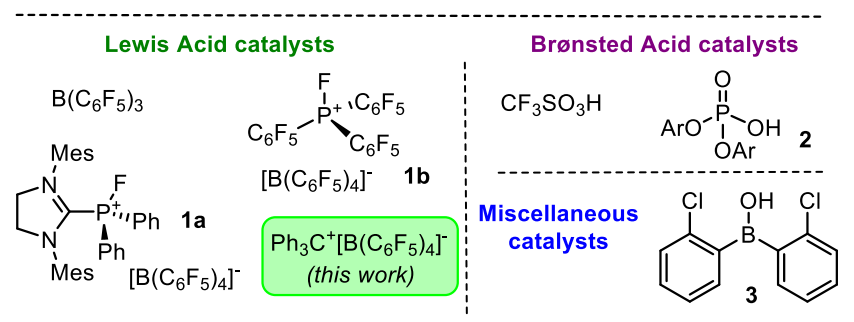

Figure 1. Catalysts for the silane-mediated reduction of phosphine oxides into phosphines.

The first reduction of a phosphine oxide into a phosphine using a silane $\left(\mathrm{Cl}_{3} \mathrm{SiH}\right)$ was reported by Fritsche in 1964. ${ }^{[11]}$ Generally, the silane requires activation and Lawrence first described in 1994 the reduction of the $\mathrm{P}=\mathrm{O}$ bond using $(\mathrm{EtO})_{3} \mathrm{SiH}$ in the presence of $\mathrm{Ti}(\mathrm{O} i-\mathrm{Pr})_{4}$ as a catalyst. ${ }^{[17]}$ Lemaire later showed that using the same catalyst, TMDS was a superior silane. ${ }^{[16]}$ In 2012 , these authors introduced $\mathrm{InBr}_{3}$ as a catalyst, ${ }^{[18]}$ which however proved non compatible with the presence of double bond attached to the P-center. $\mathrm{Cu}(\mathrm{OTf})_{2}$ described by Beller $e t$ al. solved this problem enlarging the scope of the process. ${ }^{[19]}$ More recently Oestreich, Stephan and co-workers developed a reduction catalyzed by $\mathrm{B}\left(\mathrm{C}_{6} \mathrm{~F}_{5}\right)_{3}$ or electrophilic fluorophosphonium cations $\mathbf{1 a - b},{ }^{[20]}$ which proved compatible with a broad range of functional groups. Brønsted acids such as phosphoric acids $2,{ }^{[21]}$ and $\mathrm{TfOH},{ }^{[22]}$ or borinic acids $\mathbf{3}^{[23]}$ have recently been introduced as mild catalysts for this reduction. In this context, we report herein a new simple and mild procedure to reduce phosphine oxides into phosphines using a silane as a reducer and a trityl 
cation as an initiator. Depending on the nature of the substituents on the phosphorus center, the reaction proceeds between $20^{\circ}$ to $100^{\circ} \mathrm{C}$ (or $20^{\circ} \mathrm{C}$ to $100^{\circ} \mathrm{C}$ ) and is compatible with a broad array of functional groups affording the phosphines in generally high yields.

\section{Results and Discussion}

In the course of our ongoing research on the structure and reactivity of silylium ions, ${ }^{[2]}$ we studied the behavior of these cations towards a variety of Lewis bases. We thus treated silylium ion $\mathbf{5}$, generated from the corresponding silane 4 and $\mathrm{Ph}_{3} \mathrm{C}^{+}\left[\mathrm{B}\left(\mathrm{C}_{6} \mathrm{~F}_{5}\right)_{4}\right]^{-}$with $\mathrm{Ph}_{3} \mathrm{P}=\mathrm{O}$ in deuterated $o$-chlorobenzene as a solvent. The adduct 6 was thus formed, as indicated by the strong variation of the chemical shifts in ${ }^{15} \mathrm{~N},{ }^{29} \mathrm{Si}$ and ${ }^{31} \mathrm{P}$ NMR for the respective $\mathrm{N}, \mathrm{Si}$ and $\mathrm{P}$ centers, between cation 5 and adduct 6 (Scheme 1). Addition of $\mathrm{PhSiH}_{3}$ to $\mathrm{Ph}_{3} \mathrm{PO}$ in the presence of $5 \%$ of silylium 5 led after $3 \mathrm{~h}$ at $80^{\circ} \mathrm{C}$ to $\mathrm{Ph}_{3} \mathrm{P}$ with complete conversion. A control experiment was then performed repeating the same reduction process with $\mathrm{Ph}_{3} \mathrm{C}^{+}\left[\mathrm{B}\left(\mathrm{C}_{6} \mathrm{~F}_{5}\right)_{4}\right]^{-}$, but in the absence of 4 . Surprisingly, the reaction was found to be even faster, with $\mathrm{Ph}_{3} \mathrm{P}$ obtained quantitatively in $2 \mathrm{~h}$. Finally, when the reduction of $\mathrm{Ph}_{3} \mathrm{PO}$ was carried out without catalyst, the reaction led to poor conversion after 1 day. These observations thus suggest that Lewis acidic $\mathrm{Ph}_{3} \mathrm{C}^{+}\left[\mathrm{B}\left(\mathrm{C}_{6} \mathrm{~F}_{5}\right)_{4}\right]^{-}$alone constitutes an efficient mediator for the reduction of phosphine oxides into phosphines in the presence of a silane. The role of trityl cations as Lewis acidic catalyst in organic synthesis (Diels-Alder, Mukaiyama aldol reaction...) is well documented in the literature, ${ }^{[25]}$ but has to our knowledge never been reported for the reduction of phosphine oxides. The availability of such salts and their low cost make them attractive surrogates to certain metal catalysts and more complex organocatalysts (i.e. 1a-b for instance), ${ }^{[20]}$ which prompted us to investigate more in depth their reactivity in the context of reduction of phosphine oxides.

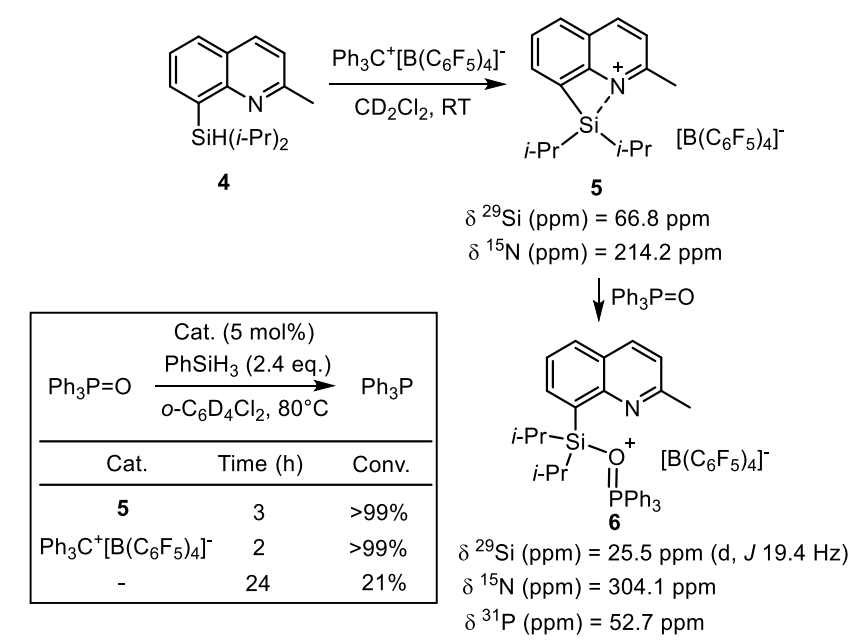

Scheme 1. Silyl cation complex with $\mathrm{Ph}_{3} \mathrm{P}=\mathrm{O}$. Silylium mediated reduction of $\mathrm{Ph}_{3} \mathrm{P}=\mathrm{O}$.

An optimization of the reaction conditions was thus carried out as detailed in Table 1 below. $\mathrm{Ph}_{3} \mathrm{PO}$ was used as a model substrate with $\mathrm{Ph}_{3} \mathrm{C}^{+}\left[\mathrm{B}\left(\mathrm{C}_{6} \mathrm{~F}_{5}\right)_{4}\right]^{-}(5 \mathrm{~mol} \%)$ as a catalyst and $\mathrm{PhSiH}_{3}$ (3 eq.) as a silane unless indicated. The reaction was performed in deuterated solvent and monitored through ${ }^{31} \mathrm{P}$ NMR. We first showed that the reaction did not proceed in the absence of catalyst (entry 1). Optimization of the solvent was then performed at $40^{\circ} \mathrm{C}$ in the presence of $d$-o-dichlorobenzene. The reaction was complete after $38 \mathrm{~h}$ (entry 2), while the kinetic was much slower in $\mathrm{CD}_{2} \mathrm{Cl}_{2}$, with only $66 \%$ conversion after $38 \mathrm{~h}$ (entry 3 ). The reactivity in $d$-benzene appeared very similar to that of $d$-o-dichlorobenzene (entry 4), while in $d$-toluene the reduction was complete after only $24 \mathrm{~h}$ (entry 5 ). By increasing the temperature, the-reaction time decreased significantly, the full conversion being reached in only 30 min. at $100^{\circ} \mathrm{C}$ (entries 6-8). For the remaining part of the optimization study, the temperature was fixed to $60^{\circ} \mathrm{C}$, in order to better estimate variation of the conversion as a function of other parameters (catalyst amount, nature of the silane,...)(Figure S1, ESI). Toluene was thus selected as the best solvent, due to its low toxicity, allowing variation of temperature as a function of the nature of the substrate. The nature of the silane was then varied, indicating that, in good agreement with literature precedent, $\mathrm{PhSiH}_{3}$ is the most active silane, providing consistently higher conversion than other silanes (entries 9-11), including PMHS (entry 12) which led to no reduction, yet regularly used in this transformation. The amount of silane was then varied from 3 eq. to 0.33 eq. (Figure S2, ESI). The conversion is complete with 2 and 1 eq. of silane (entries 13-14), although the reaction rate decreases, while only $58 \%$ and $22 \%$ conversion were observed with 0.66 and 0.33 eq. respectively (entries $15-16$ ), suggesting that only one atom of hydrogen is transferred from the silane (vide infra). The optimization was then continued with 1 eq. of silane. The nature of the counter-anion was thus studied changing the $\mathrm{B}\left(\mathrm{C}_{6} \mathrm{~F}_{5}\right)_{4}$ anion for the less expensive $\mathrm{BF}_{4}$. $\mathrm{Ph}_{3} \mathrm{C}^{+}\left[\mathrm{BF}_{4}\right]^{-}$is not soluble in toluene and the conversion is null under these conditions. Prior solubilisation of 
$\mathrm{Ph}_{3} \mathrm{C}^{+}\left[\mathrm{BF}_{4}\right]^{-}$in a $\mathrm{CD}_{2} \mathrm{Cl}_{2}-d$-Toluene mixture allowed the reaction to progress but the conversion never exceeded $25 \%$ (entry 17). $\mathrm{PF}_{6}{ }^{-}$and $\mathrm{SnCl}_{5}{ }^{-}$were also tested as counter-anions (entries 18-19) and found less efficient than $\left[\mathrm{B}\left(\mathrm{C}_{6} \mathrm{~F}_{5}\right)_{4}\right]^{-}$(entry 6 ), leading respectively to $93 \%$ and $95 \%$ conversion, albeit after $24 \mathrm{~h}$, indicating that the presence of a weakly coordinating anion is crucial for the catalytic efficiency. ${ }^{[26]}$ The catalyst loading was also varied indicating that a decrease of the quantity of the trityl salt was detrimental to the rate of the reaction (entries 20-21). The amount of solvent is also an important parameter for large scale application. Therefore, we investigated the effect of concentration on the rate of the reaction. As indicated in entry 22 , dilution to $0.36 \mathrm{M}$ significantly decreased the conversion into phosphine, while in contrast and as expected, complete conversion and shorter reaction time were observed in more concentrated media (entries 23-24).

Table 1. Optimization of the $\mathrm{Ph}_{3} \mathrm{P}=\mathrm{O}$ reduction.

\begin{tabular}{|c|c|c|c|c|c|}
\hline \multirow[b]{2}{*}{ entry } & \multirow[t]{2}{*}{$\mathrm{Ph}_{3} \mathrm{P}=\mathrm{O}$} & \multicolumn{3}{|c|}{$\underset{\text { olvent, } \mathrm{T}\left({ }^{\circ} \mathrm{C}\right) \text {, time }}{\mathrm{R}} \mathrm{Ph}_{3} \mathrm{P}$} & \multirow[b]{2}{*}{$\begin{array}{l}\text { Conv. } \\
(\%)^{a)}\end{array}$} \\
\hline & & $\begin{array}{l}\mathrm{T} \\
\left({ }^{\circ} \mathrm{C}\right)\end{array}$ & $\begin{array}{l}\text { Time } \\
\text { (h) }\end{array}$ & $\mathrm{Si}-\mathrm{H}$ & \\
\hline 1 & $d$-Toluene & 60 & 6.5 & $\mathrm{PhSiH}_{3}{ }^{\text {b) }}$ & - \\
\hline 2 & $o-\mathrm{C}_{6} \mathrm{D}_{4} \mathrm{Cl}_{2}$ & 40 & 38 & $\mathrm{PhSiH}_{3}{ }^{\mathrm{c})}$ & $>99$ \\
\hline 3 & $\mathrm{CD}_{2} \mathrm{Cl}_{2}$ & 40 & 38 & $\mathrm{PhSiH}_{3}$ & 66 \\
\hline 4 & $\mathrm{C}_{6} \mathrm{D}_{6}$ & 40 & 38 & $\mathrm{PhSiH}_{3}$ & $>99$ \\
\hline 5 & $d$-Toluene & 40 & 24 & $\mathrm{PhSiH}_{3}$ & $>99$ \\
\hline 6 & $d$-Toluene & 60 & 4.5 & $\mathrm{PhSiH}_{3}$ & $>99$ \\
\hline 7 & $d$-Toluene & 80 & 1.5 & $\mathrm{PhSiH}_{3}$ & $>99$ \\
\hline 8 & $d$-Toluene & 100 & 0.5 & $\mathrm{PhSiH}_{3}$ & $>99$ \\
\hline 9 & $d$-Toluene & 60 & 4.5 & $\mathrm{Et}_{3} \mathrm{SiH}$ & - \\
\hline 10 & $d$-Toluene & 60 & 4.5 & $\mathrm{Ph}_{2} \mathrm{SiH}_{2}$ & 6 \\
\hline 11 & $d$-Toluene & 60 & 4.5 & $(\mathrm{EtO})_{2} \mathrm{MeSiH}$ & 1 \\
\hline 12 & $d$-Toluene & 60 & 4.5 & PMHS & - \\
\hline 13 & $d$-Toluene & 60 & 5 & $\mathrm{PhSiH}_{3}{ }^{\text {d) }}$ & $>99$ \\
\hline 14 & $d$-Toluene & 60 & 6.5 & $\mathrm{PhSiH}_{3}{ }^{\text {e) }}$ & $>99$ \\
\hline 15 & $d$-Toluene & 60 & 6 & $\mathrm{PhSiH}_{3}{ }^{\mathrm{f})}$ & 58 \\
\hline 16 & $d$-Toluene & 60 & 72 & $\left.\mathrm{PhSiH}_{3} \mathrm{~g}\right)$ & 22 \\
\hline 17 & $d$-Tol- $\mathrm{CD}_{2} \mathrm{Cl}_{2}$ & 40 & 6.5 & $\mathrm{PhSiH}_{3} \mathrm{~h}^{\text {) }}$ & 24 \\
\hline 18 & $d$-Toluene & 60 & 24 & $\mathrm{PhSiH}_{3}{ }^{\text {i) }}$ & 93 \\
\hline 19 & $d$-Toluene & 60 & 24 & $\left.\mathrm{PhSiH}_{3}{ }^{\mathrm{j}}\right)$ & 95 \\
\hline 20 & $d$-Toluene & 60 & 6.5 & $\left.\mathrm{PhSiH}_{3}{ }^{\mathrm{k}}\right)$ & 37 \\
\hline 21 & $d$-Toluene & 60 & 6.5 & $\mathrm{PhSiH}_{3}{ }^{\mathrm{l})}$ & 14 \\
\hline 22 & $d$-Toluene & 60 & 6.5 & $\mathrm{PhSiH}_{3}{ }^{\mathrm{m})}$ & 60 \\
\hline 23 & $d$-Toluene & 60 & 6.5 & $\mathrm{PhSiH}_{3}{ }^{\mathrm{n})}$ & $>99$ \\
\hline 24 & $d$-Toluene & 60 & 4.5 & $\mathrm{PhSiH}_{3}{ }^{\text {o) }}$ & $>99$ \\
\hline
\end{tabular}

a) Conversion was estimated through ${ }^{31} \mathrm{P}$ NMR. ${ }^{\text {b) }}$ No catalyst. ${ }^{\text {c) }}$ Unless indicated, standard conditions were as follows: $\mathrm{Ph}{ }_{3} \mathrm{PO}$ (1 eq.), silane (3 eq.), $\mathrm{Ph}_{3} \mathrm{C}^{+}\left[\mathrm{B}\left(\mathrm{C}_{6} \mathrm{~F}_{5}\right)_{4}\right]^{-}(5 \mathrm{~mol} \%)$ in the indicated solvent $(0.7 \mathrm{~mL}) .{ }^{\mathrm{d})} 2$ eq. of silane was used. ${ }^{\text {e) }} 1$ eq. of silane was used. ${ }^{\text {f) }} 0.66$ eq. of silane was used. ${ }^{\text {g) }} 0.33$ eq. of silane was used. ${ }^{\text {h) }} \mathrm{Ph}_{3} \mathrm{C}^{+} \mathrm{BF}_{4}^{-}(5 \mathrm{~mol} \%)$ and silane (1 eq.) were used. i) $\mathrm{Ph}_{3} \mathrm{C}^{+} \mathrm{PF}_{6}^{-}(5 \mathrm{~mol} \%)$ and silane (1 eq.) were used. ${ }^{\mathrm{j})} \mathrm{Ph}_{3} \mathrm{C}^{+} \mathrm{SnCl}_{5}^{-}(5 \mathrm{~mol} \%)$ and silane (1 eq.) were used. ${ }^{\mathrm{k})} \mathrm{Ph}_{3} \mathrm{C}^{+}\left[\mathrm{B}^{-}\left(\mathrm{C}_{6} \mathrm{~F}_{5}\right)_{4}\right]^{-}(2.5$ mol\%). ${ }^{1)} \mathrm{Ph}_{3} \mathrm{C}^{+}\left[\mathrm{B}\left(\mathrm{C}_{6} \mathrm{~F}_{5}\right)_{4}\right]^{-}(1 \mathrm{~mol} \%) .{ }^{\mathrm{m})} 0.36 \mathrm{M} .{ }^{\mathrm{n})} 0.5 \mathrm{M} .{ }^{\circ)} 0.9 \mathrm{M}$.

Interestingly, when the process was repeated without special caution (glove box), the starting substrates being handled in the air, the conversion remained the same. This is of interest for the large-scale synthesis of arylphosphines known to be less readily oxidized than alkylphosphines (vide infra). Finally, it is worthy of note that our catalyst compares well with $\mathrm{B}\left(\mathrm{C}_{6} \mathrm{~F}_{5}\right)_{3}(5 \mathrm{~mol} \%)$ and fluorophosphonium salts 1a-b $(2 \mathrm{~mol} \%)$, which, in the presence of $\mathrm{PhSiH}_{3}$ (3 eq.), led to $\mathrm{PPh}_{3}$ with $99 \%$ conversion in $20 \mathrm{~h}$ and $24 \mathrm{~h}$ respectively, ${ }^{[20]}$ while $\mathrm{Ph}_{3} \mathrm{C}^{+}\left[\mathrm{B}\left(\mathrm{C}_{6} \mathrm{~F}_{5}\right)_{4}\right]^{-}$ $(5 \mathrm{~mol} \%)$ reached the same conversion in $1.5 \mathrm{~h}$ at $80^{\circ} \mathrm{C}$.

With our optimal conditions in hand, a series of secondary and tertiary monophosphine oxides were reduced (Table 2). The majority of the products were easily reduced at $80^{\circ} \mathrm{C}$ with full conversion and isolated yields ranging between 92 and 95\%, except for the much-hindered substrates (Table 2, entries 4-6 and 8). For $o$-substituted phosphine oxide 7e (entry 5), a low yield of $23 \%$ was however obtained after heating the reaction mixture to $100^{\circ} \mathrm{C}$ for 4 days (entry 5). For arylphosphine oxides bearing electron-withdrawing (7b) and donating groups (7c) on the para-position, higher reaction times were necessary (entries 2-3). Interestingly, the resulting phosphines $\mathbf{8 b}$ and $\mathbf{8 c}$, 
were thus obtained in excellent yields at $80^{\circ} \mathrm{C}$ but in only $63 \%$ and $82 \%$ respectively after 24 and $16 \mathrm{~h}$ at $60^{\circ} \mathrm{C}$, again pointing out the importance of the temperature. While free triarylphosphines may be isolated through simple chromatography, their aliphatic analogues require complexation as phosphine-boranes prior to purification. It is however worth noticing that $\mathrm{Et}_{3} \mathrm{P}-\mathrm{BH}_{3} \mathbf{8 k}$ even oxidises spontaneously under this form. Aliphatic oxides are converted with good kinetics, except sterically more hindered precursors such as $7 \mathbf{i}$ (entry 9 ). $(n-\mathrm{Bu})_{3} \mathrm{PO} \mathbf{7} \mathbf{j}$ is effectively known to be reduced by $\mathrm{PhSiH}_{3}$ in the absence of any catalyst. However, a $96 \%$ conversion was reached after $27 \mathrm{~h}$ at $80^{\circ} \mathrm{C}$, while a similar yield was obtained after only $1 \mathrm{~h}$ in the presence of the trityl catalyst (entry 10). Secondary phosphine oxide $\mathbf{7 l}$ was efficiently converted at room temperature into the corresponding phosphine, isolated as its borane salt $\mathbf{8} \mathbf{l}$ in excellent yield (entry 12). Finally, a scaling up of the process was performed with the reduction of $5 \mathrm{mmol}$ of $\mathrm{Ph}_{3} \mathrm{PO} \mathbf{7 a}$ and $(n-\mathrm{Bu})_{3} \mathrm{PO} \mathbf{7 j}$, which led to the corresponding phosphines in high yields in only $2 \mathrm{~h}$ at $80^{\circ} \mathrm{C}$ (entries $\left.13-14\right)$.

Table 2. Reduction of secondary and tertiary monophosphine oxides.

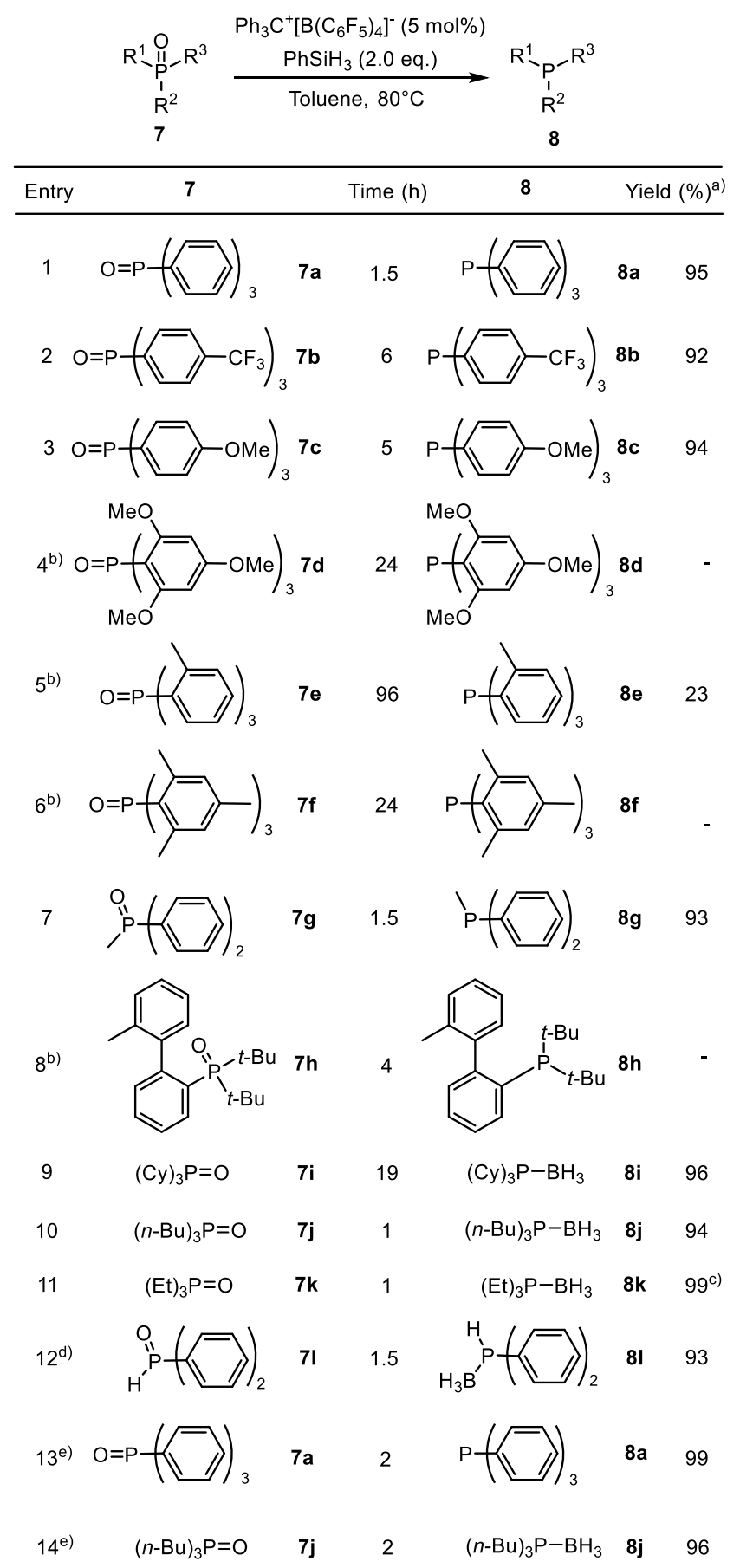
a) Isolated yields. ${ }^{\text {b) }}$ Reaction performed at $100^{\circ} \mathrm{C} .{ }^{\text {c) }} \mathrm{NMR}$ yield as $\mathbf{8 k}$ was oxidized upon purification through silica gel
chromatography. ${ }^{\text {d) }}$ Reaction performed at $20^{\circ} \mathrm{C}$. ${ }^{\text {e) }}$ Reaction performed on 5 mmol scale. 
Tertiary bis-phosphines were also submitted to our optimized conditions, by using 4 eq. of $\mathrm{PhSiH}_{3}$ (Table 3). BINAP bis-oxide 9a was thus reduced into the desired BINAP, albeit in modest yield due to steric hindrance (entry 1). Diarylalkyldiphosphine $\mathbf{9 b}$ was reduced into the corresponding diphosphine $\mathbf{1 0 b}$ in a much better yield (entry 2). Interestingly, a longer reaction time was however required for the monoxide $9 \mathrm{c}$ using 2 eq. of $\mathrm{PhSiH}_{3}$, which led to 10b in $90 \%$ yield (entry 3). Unsaturated diphosphine oxides were also reduced chemoselectively into diphosphines 10c-d in moderate yields (entries 4-5), leaving the double and triple bonds unchanged, in contrast with observations of Oestreich and Stephan with catalysts 1a-b ${ }^{[20]}$ which led to complex mixtures with these substrates.

Table 3. Reduction of tertiary bis-phosphine oxides.

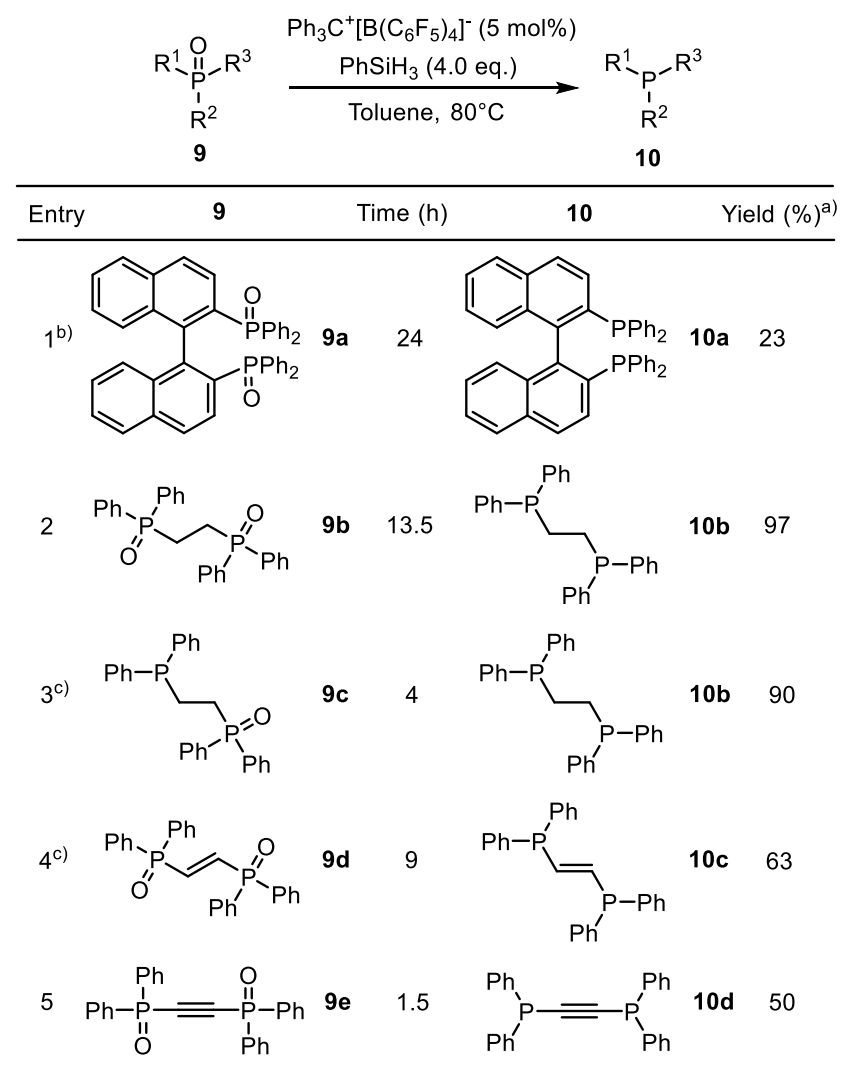

a) Isolated yields. ${ }^{\text {b) }}$ Reaction performed at $100^{\circ} \mathrm{C}^{\text {c) }} 2$ eq. of $\mathrm{PhSiH}_{3}$ were used.

As indicated above, the $\mathrm{CF}_{3}$ group of the oxide $\mathbf{7 b}$ was left unchanged under our mild conditions, despite the known affinity of reactive silicon species (including silyl cations) for fluorine. ${ }^{[27]}$ Similarly, no hydrosilylation of the double and triple bonds of 9d-e respectively was observed during this reduction, ${ }^{[28]}$ indicating a high compatibility of our reductive process with these functional groups. In order to explore more in depth this chemoselectivity, the reaction was extended to several precursors possessing other functional groups that the phosphine oxide. Results of this investigation are gathered in Table 4 and Scheme 2 below. For instance, electron-rich heterocycles including furane and pyridines were not reduced by the trityl salt/silane couple (Table 4, entries 1-2). The carboxylic acid and the nitrile functions were not reduced either under the reductive conditions (entries 4 and 8), with selectivity > 99:1, likely as a result of the higher Lewis basicity of the phosphine oxide function (see mechanistic discussion). However, and in contrast, reduction of phosphine oxide $\mathbf{1 1 g}$ led to the double reduction of the aldehyde and $\mathrm{P}=\mathrm{O}$ groups (entry 7). A careful monitoring of the reaction through ${ }^{31} \mathrm{P}$ NMR (See ESI), indicates that the $\mathrm{P}=\mathrm{O}$ bond is reduced first and the phosphine-aldehyde obtained as an intermediate, which after $1.5 \mathrm{~h}$ is further reduced into phosphine-alcohol 12g. A control experiment was then performed, treating a 1:1 mixture of benzaldehyde and $\mathrm{Ph}_{3} \mathrm{P}=\mathrm{O}$ under our standard conditions (Trityl salt (5 mol\%), $\mathrm{PhSiH}_{3}$ (2 eq.)) (Scheme 2). The NMR of the reaction mixture showed that only the phosphine oxide was reduced, suggesting that a proximity effect was responsible for the further reduction of the aldehyde function in $\mathbf{1 1 g}$, likely through coordination of a "silicon-hydride" reducing species by the ortho-phosphorus center. It can therefore be concluded that aldehydes are compatible with these reductive conditions. Bromide 11e (entry 5) was also reduced without debromination into 12e in high yield and only $30 \mathrm{~min}$, further substantiating the proximity effect mentioned above. Finally, the amino group was also found compatible with the reduction conditions, with the reduction of $\mathbf{1 1 f}$ into $\mathbf{1 2 f}$ (entry 6). 
Table 4. Reduction of functionalized phosphine oxides.

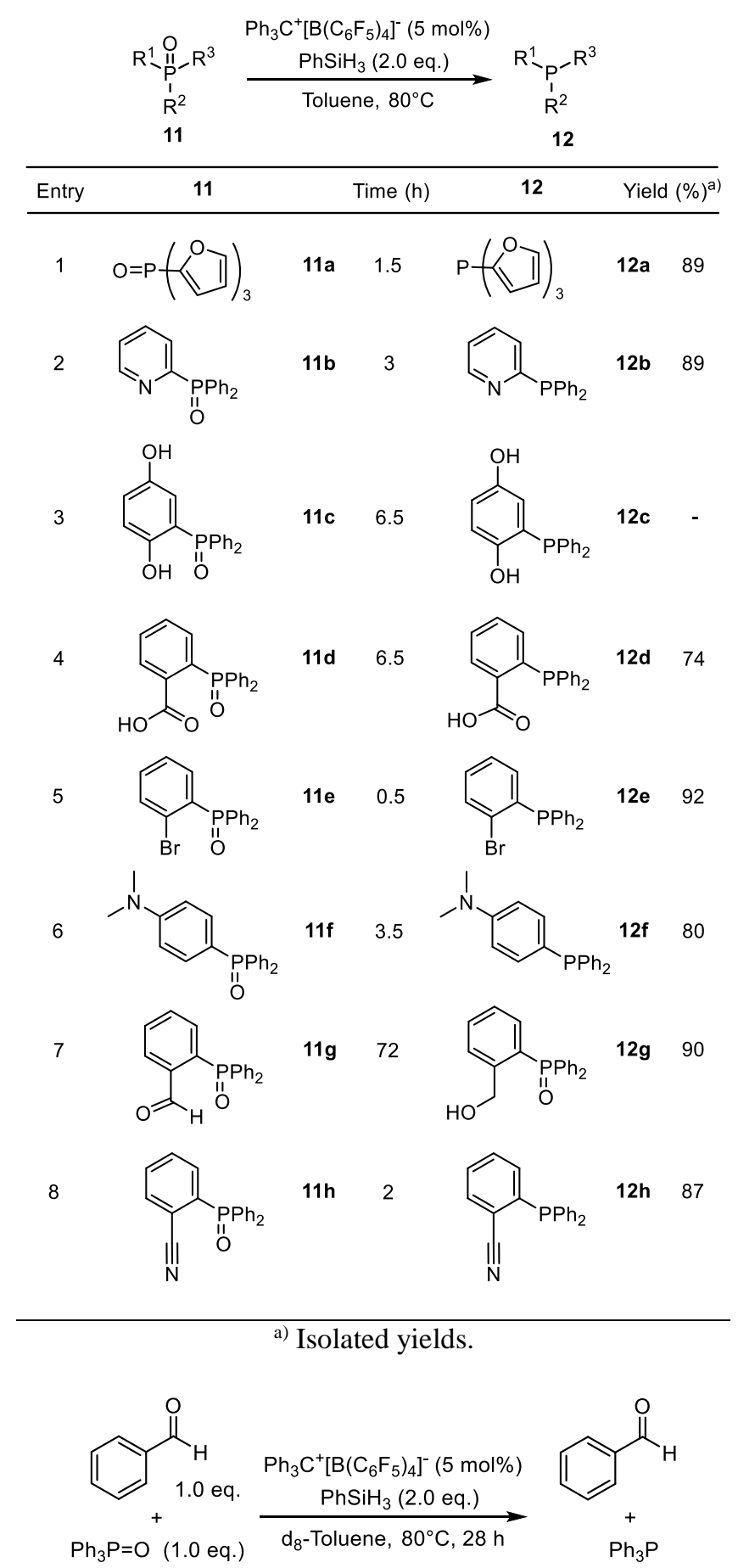

Scheme 2. Competitive trityl salt/silane mediated reduction of $\mathrm{Ph}_{3} \mathrm{P}=\mathrm{O}$ and benzaldehyde.

In a last step, we studied the compatibility of our reaction conditions with the P-centered chirality. ${ }^{[7]}$ We first prepared an enantioenriched secondary phosphine oxide 13 (76\% e.e.), ${ }^{[29]}$ which was subjected to our reduction conditions (Scheme 3). The desired phosphane $\mathbf{1 4}^{[30]}$ was thus isolated in good yield, albeit as a racemic mixture. The energy barrier for the inversion of configuration is relatively low for secondary phosphanes $\left(\Delta \mathrm{G}=23 \mathrm{kcal}^{\mathrm{mol}} \mathrm{mol}^{-}\right.$

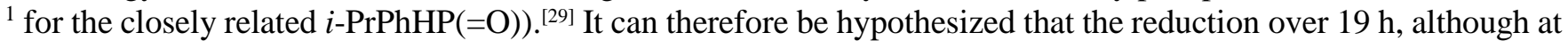
room temperature, may be sufficient to allow for the racemization of the phosphine under these conditions. ${ }^{[31]}$ The study was thus extended to configurationally more stable $\left(\Delta \mathrm{G}=32 \mathrm{kcal}^{\mathrm{mol}}{ }^{-1}\right.$ for $i$-PrPhMeP $\left.(=\mathrm{O})\right)$ chiral tertiary phosphine oxide 15 (e.e. 68\%), prepared from a second batch of 13 (e.e. 72\%). ${ }^{[32]}$ Upon treatment under above optimized conditions, 15 led to the desired phosphine 16, isolated in good yield as its borane salt. The process was carried out at two different temperatures, showing that a loss of chiral information was observed when the reaction was kept for a longer time under the reductive conditions. ${ }^{[33]}$ As the evaluation of the enantiomeric purity of $\mathbf{1 6}$ was not possible through chiral HPLC, $\mathbf{1 6}$ was thus reoxidized with $m$-CPBA into $\mathbf{1 5}$ and separation of its enantiomers 
carried out through chiral HPLC, showing that the whole sequence finally led to complete racemization of $\mathbf{1 5}$. It is premature at this stage to conclude which step is responsible for racemization, as both borane protection and oxidation with $m$-CPBA were reported to occur with retention of the configuration at the phosphorus center. ${ }^{[34]}$ The value of optical rotations indicates that if racemization occurred during reduction of $\mathbf{1 5}$, it was not complete. Considering these results, reduction of the known DIPAMP oxide 17 was then carried out. Results are somehow puzzling, with the formation of DIPAMP $18 \mathbf{a}^{[35]}$ and its meso isomer $\mathbf{1 8 b}$, the structure of which was secured through X-ray diffraction studies (see ESI). 18a/18b Ratio was shown to vary depending on temperature and time as indicated in Scheme 3. We were not able to evaluate the enantiomeric purity of 18a through chiral HPLC, due its sensitivity to oxygen. Optical rotation of the mixture $\left([\alpha]_{\mathrm{D}}^{25}=-48.6^{\circ}\right)$ indicates that if racemization occurred, as above for 15, it was not complete. More interestingly, when pure DIPAMP 18a was heated at $100^{\circ} \mathrm{C}$ in the presence of 2 eq. of $\mathrm{PhSiH}_{3}$ and $5 \mathrm{~mol} \%$ of the trityl salt, a mixture of $\mathbf{1 8 \mathbf { a }}$ and $\mathbf{1 8 b}$ in a $6: 4$ ratio was observed, indicating that epimerization occurs after reduction, in agreement with recent work by Holz, Börner and co-workers who showed that arylphosphines racemize more easily than alkylphosphines ${ }^{[31]}$ In summary, these experiments suggest that our conditions do not allow a complete preservation of the configuration of the phosphorus center as the final phosphanes undergo racemization to some extent. ${ }^{[31]}$
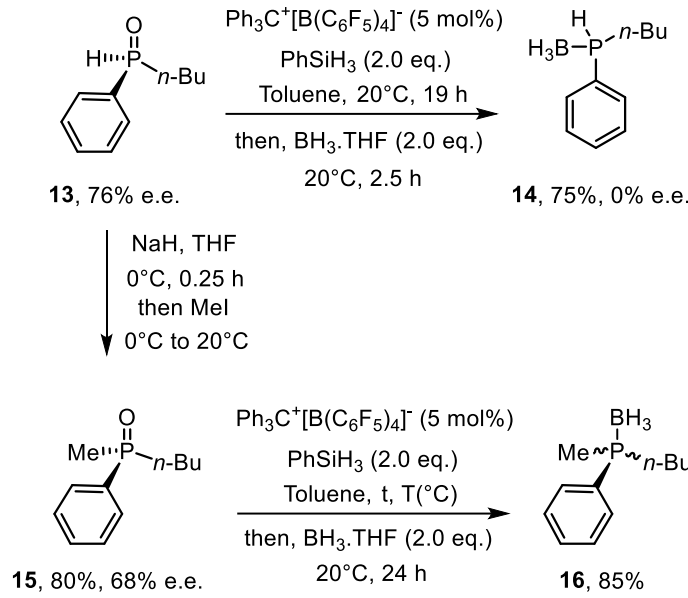

$1.5 \mathrm{~h}, 80^{\circ} \mathrm{C}[\alpha]_{\mathrm{D}}{ }^{25}=-16.4^{\circ}\left(\mathrm{c}=0.11, \mathrm{CHCl}_{3}\right)$

$8 \mathrm{~h}, 50^{\circ} \mathrm{C}[\alpha]_{\mathrm{D}}^{25}=-4.8^{\circ}\left(\mathrm{c}=0.11, \mathrm{CHCl}_{3}\right)$

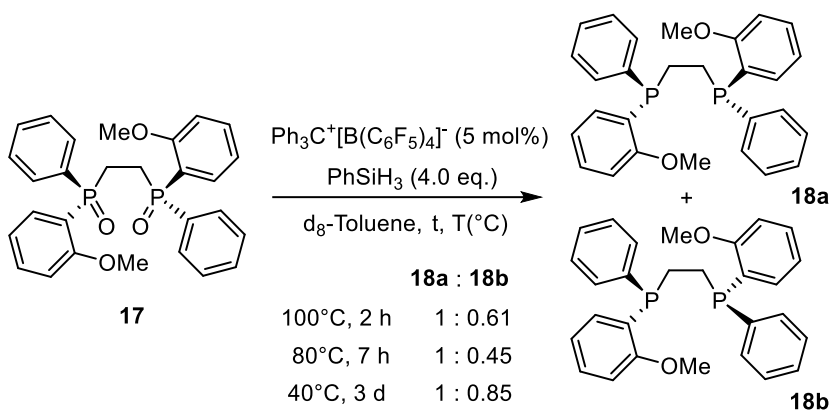

Scheme 3. Trityl salt/silane mediated reduction of chiral phosphine oxides.

As mentioned at the beginning of the article, silyl cations generated through abstraction of a hydrogen from a silane by the trityl cation spontaneously coordinate with phosphine oxides and might thus serve as efficient initiators for the reaction (Scheme 1 and 5, vide infra). However, we observed during optimization of the process that the order of addition of the reagents was crucial for a successful reduction. As indicated in the experimental part, the best results were obtained when the trityl salt was first added to the phosphine oxide and the silane added last. Association between the silane and the trityl cation prior to the addition of the oxide led to a complex reaction mixture. We thus studied through ${ }^{1} \mathrm{H}$ and ${ }^{31} \mathrm{P}$ NMR (ESI) the behavior of $\mathrm{Ph}_{3} \mathrm{C}^{+}\left[\mathrm{B}\left(\mathrm{C}_{6} \mathrm{~F}_{5}\right)_{4}\right]^{-}$in the presence of $\mathrm{Et}_{3} \mathrm{PO}$, by mixing 1 eq. of the trityl salt with 2 eq. of $\mathrm{Et}_{3} \mathrm{PO}$ in $d_{8}$-Toluene at $20^{\circ} \mathrm{C}$. A 2:1 adduct 19 was formed resulting from the complexation of the trityl cation with the Lewis basic phosphine oxide, followed by a further stabilization of the phosphonium intermediate by the formation of second $\mathrm{P}-\mathrm{O}$ bond. The formation of $\mathbf{1 9}$ is supported by the observation of two signals in ${ }^{31} \mathrm{P} N \mathrm{NMR}$ at 56 and $69.3 \mathrm{ppm}$ instead of the chemical shift at $\delta=49.1 \mathrm{ppm} \mathrm{for} \mathrm{Et}_{3} \mathrm{PO}$ and by the shielding of the $-\mathrm{CH}_{2}$ and $\mathrm{CH}_{3}$ groups of the ethyl of $\mathrm{Et}_{3} \mathrm{PO}$, indicating an electron depletion at the phosphorus center in the phosphonium moiety. Addition of $\mathrm{PhSiH}_{3}$ (1 eq.) to 19 then led to the release of hydrogen 
detectable on the ${ }^{1} \mathrm{H}$ NMR spectrum of the reaction mixture $\left(\delta^{1} \mathrm{H}=4.5 \mathrm{ppm}\right)$, along with $\mathrm{Et}_{3} \mathrm{P}$ as the only species bearing a phosphorus center, in good agreement with high yields of phosphines generally observed during the study (ESI). $\mathrm{Ph}_{3} \mathrm{CH}$ was also observed, although in smaller amount than expected. Unreacted silane was also detected on the crude ${ }^{1} \mathrm{H}$ NMR along with 3 signals in the 4-5 ppm region indicative of other $\mathrm{Si}-\mathrm{H}$ containing compounds. ${ }^{1} \mathrm{H}-$ ${ }^{29} \mathrm{Si} \mathrm{HSQC}$ and HMBC NMR studies were then performed showing that $\left(\mathrm{PhSiH}_{2}\right)_{2} \mathrm{O}$ and oligomeric siloxanes $(\mathrm{PhSiH})_{\mathrm{n}} \mathrm{O}$ were effectively formed (see ESI). ${ }^{[36]}$ Signals of a third compound at $-37.8 \mathrm{ppm}$ in ${ }^{29} \mathrm{Si}$ and $85.9 \mathrm{ppm}$ in ${ }^{13} \mathrm{C}$ NMR (close to that of $\mathrm{Ph}_{3} \mathrm{COH}$ at $81.7 \mathrm{ppm}$ ) were attributed to the formation of $\mathrm{PhSiH}_{2} \mathrm{OCPh}_{3}$ 20, explaining the low amount of $\mathrm{Ph}_{3} \mathrm{CH}$ observed. Phosphonium 19 was also isolated and tested as a putative catalyst for the reduction of $\mathrm{Ph}_{3} \mathrm{PO}$ in toluene at $80^{\circ} \mathrm{C}$. Under these conditions, only $33 \%$ conversion of $7 \mathbf{a}$ was reached after $2 \mathrm{~h}$, indicating that $\mathbf{1 9}$ is likely not the "true catalyst" for this reduction. ${ }^{[20]}$ The formation of $\mathbf{2 0}$ may be rationalized by the sequence depicted in Scheme 4. Reaction of $\mathbf{1 9}$ with $\mathrm{PhSiH}_{3}$ would proceed through approach of the silane as in $\mathbf{I}^{\#}$, generating the phosphonium intermediate $\mathbf{I}$ and $\mathbf{2 0}$. A closely related pathway was proposed for the reduction of $\mathrm{R}_{3} \mathrm{PO}$ with $\mathrm{PhSiH}_{3} \cdot{ }^{[37]}$ Reaction of $\mathbf{I}$ with excess $\mathrm{PhSiH}_{3}$ would then release hydrogen along with the $\mathrm{PhSiH}_{2}{ }^{+}$ cation complexed by the free phosphine (e.g. II). This highly reactive silyl cation, thus stabilized, would initiate the reduction process as proposed below in $\mathrm{Scheme}^{2}$. The $\mathrm{PhSiH}_{2}{ }^{+}$may also be simply generated through the classical J. Y. Corey reaction ${ }^{38}$ between $\mathrm{PhSiH}_{3}$ and the trityl salt.

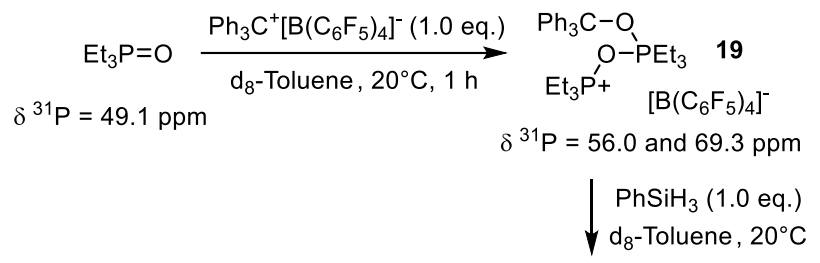

$$
\begin{aligned}
& \mathrm{Et}_{3} \mathrm{P}+\mathrm{H}_{2}+(\mathrm{PhSiH})_{n} \mathrm{O}+\left(\mathrm{PhSiH}_{2}\right)_{2} \mathrm{O} \\
& +\mathrm{Ph}_{3} \mathrm{CO}-\mathrm{SiH}_{2} \mathrm{Ph}+\mathrm{Ph}_{3} \mathrm{CH} \\
& 20
\end{aligned}
$$

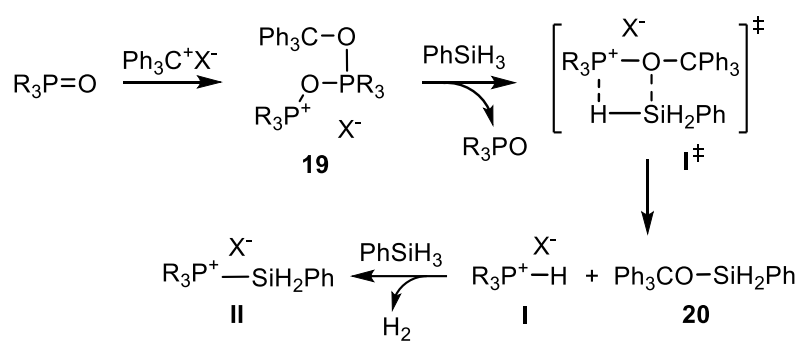

Scheme 4. Mechanistic investigation on the trityl/silane couple mediated phosphine oxide reduction $\left(\mathrm{X}^{-}:\left[\mathrm{B}\left(\mathrm{C}_{6} \mathrm{~F}_{5}\right)_{4}\right]^{-}\right)$.

A tentative mechanism was finally proposed based on mechanistic experiments above and literature precedent on Lewis acid/silane mediated reduction of phosphine oxides. ${ }^{[7]}$ The reaction would start with the generation of $\mathrm{PhSiH}_{2}{ }^{+}$, likely stabilized by a Lewis base present in the medium $\left(\mathrm{R}_{3} \mathrm{PO}, \mathrm{R}_{3} \mathrm{P}\right.$, toluene,...), and thus written as $\mathrm{PhSiH}_{2}{ }^{+} \leftarrow \mathrm{L}$ II. The coordination of $\mathrm{PhSiH}_{2}{ }^{+}$with the strongest Lewis base $\mathrm{R}_{3} \mathrm{P}=\mathrm{O}$ would then form intermediate III. Intermolecular hydride migration from $\mathrm{PhSiH}_{3}$ to III (through III ${ }^{\#}$ ) would then give IV, a known intermediate in these reductions, along with silylium $\mathrm{PhSiH}_{2}{ }^{+}$regenerating species III through coordination with $\mathrm{R}_{3} \mathrm{P}=\mathrm{O}$. Pietrusiewicz et al. during their theoretical studies on the reduction of $\mathrm{R}_{3} \mathrm{P}=\mathrm{O}$ with $\mathrm{PhSiH}_{3}$ showed that IV evolved through a transition state, with the $\mathrm{P}-\mathrm{O}$ and $\mathrm{P}-\mathrm{H}$ bonds broken in a concerted manner, ${ }^{\left[{ }^{[3]}\right.}$ affording the phosphine, along with $\mathrm{PhSiH}_{2} \mathrm{OH}$. Silanols are known to convert readily into siloxanes explaining the formation of $\left(\mathrm{PhSiH}_{2}\right)_{2} \mathrm{O}$ and polysiloxanes. ${ }^{[36]}$ Excess $\mathrm{PhSiH}_{3}$ may also react with $\mathrm{PhSiH}_{2} \mathrm{OH}$ to generate siloxanes and explain the presence of $\mathrm{H}_{2}$ released during the reaction. 


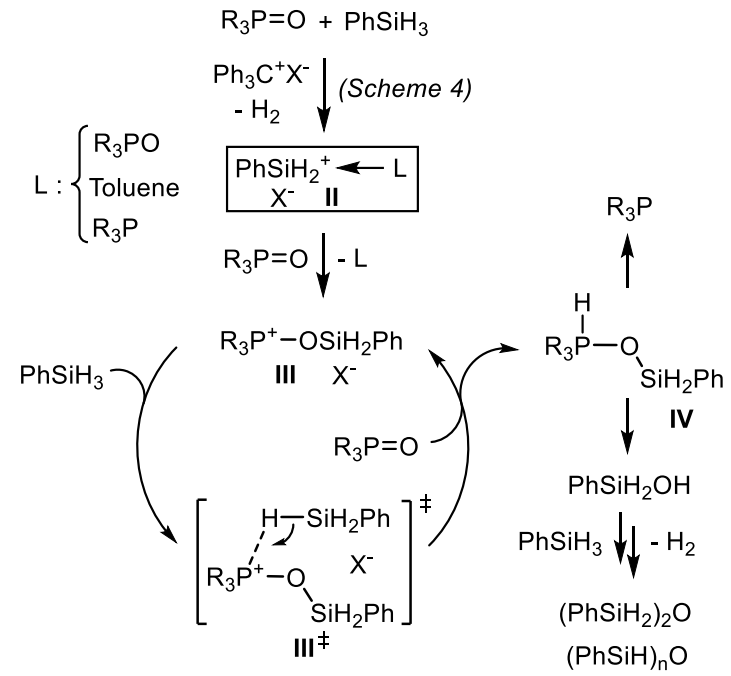

Scheme 5. Proposed mechanism for the reduction of phosphine oxides using trityl salts and silanes.

\section{Conclusion}

As a summary, we described here a simple and efficient method to reduce phosphine oxides into the corresponding phosphines using $\mathrm{PhSiH}_{3}$ as a reducing agent and $\mathrm{Ph}_{3} \mathrm{C}^{+}\left[\mathrm{B}\left(\mathrm{C}_{6} \mathrm{~F}_{5}\right)_{4}\right]^{-}$as an initiator. A broad range of substrates bearing various functional groups may thus be reduced, generally in high and reproducible yields. Limitations include sterically hindered substrates and the loss of configuration at the phosphorus center during reduction of P-stereogenic precursors, likely resulting from the low configuration stability of the resulting phosphines under the thermal conditions. A tentative mechanism was finally proposed based on the generation of a putative silylium cation stabilized by Lewis bases in the medium, which reacts with the phosphine oxide precursor to form a phosphonium salt eventually reduced by the silane.

\section{Experimental Section}

Triphenylphosphine oxide - silylium 5 complex (6). In a glovebox under an argon atmosphere, a solution of $\mathrm{Ph}{ }_{3} \mathrm{C}^{+}\left[\mathrm{B}\left(\mathrm{C}_{6} \mathrm{~F}_{5}\right)_{4}\right]^{-}$ (46.9 mg, $0.05 \mathrm{mmol}, 1.0$ eq.) in $\mathrm{CD}_{2} \mathrm{Cl}_{2}(0.3 \mathrm{~mL})$, was added to the silane 4 (13.1 mg, $0.05 \mathrm{mmol}, 1.0$ eq.) and then injected into a dry J-Young NMR tube. Then dry triphenylphosphine oxide (13.9 mg, $0.05 \mathrm{mmol}, 1.0$ eq.) in solution in $\mathrm{CD}_{2} \mathrm{Cl}_{2}(0.2$ $\mathrm{mL}$ ) was added to the tube at room temperature. The tube was tightly closed, shaken, and then NMR spectroscopies were recorded. ${ }^{1} \mathrm{H}$ NMR $(600 \mathrm{MHz}, d$-o-Dichlorobenzene) $\delta 7.66(\mathrm{~d}, J=8.4 \mathrm{~Hz}, 1 \mathrm{H}), 7.59(\mathrm{dd}, J=6.9,1.4 \mathrm{~Hz}, 1 \mathrm{H}), 7.56(\mathrm{dd}, J=$ 8.1, 1.4 Hz, 1H), $7.49-7.36(\mathrm{~m}, 10 \mathrm{H}), 7.31-7.24(\mathrm{~m}, 4 \mathrm{H}), 7.23(\mathrm{dd}, J=8.1,6.9 \mathrm{~Hz}, 1 \mathrm{H}), 7.18-7.10(\mathrm{~m}, 6 \mathrm{H}), 7.11-7.05$ $(\mathrm{m}, 3 \mathrm{H}), 7.05-7.00(\mathrm{~m}, 6 \mathrm{H}), 6.93(\mathrm{~d}, \mathrm{~J}=8.4 \mathrm{~Hz}, 1 \mathrm{H}), 5.41(\mathrm{~s}, 1 \mathrm{H}), 2.38(\mathrm{~s}, 3 \mathrm{H}), 1.73-1.66(\mathrm{~m}, 2 \mathrm{H}), 1.02(\mathrm{~d}, J=7.5 \mathrm{~Hz}, 6 \mathrm{H})$, $0.87(\mathrm{~d}, J=7.5 \mathrm{~Hz}, 6 \mathrm{H}) .{ }^{13} \mathrm{C}$ NMR $(151 \mathrm{MHz}, d$-o-Dichlorobenzene) $\delta 158.6,151.5,148.7(\mathrm{~d}, J=241.8 \mathrm{~Hz}), 144.0,138.5(\mathrm{~d}$, $J=245.6 \mathrm{~Hz}), 137.0,136.6(\mathrm{dm}, J=245.0 \mathrm{~Hz}), 136.6,135.8(\mathrm{~d}, J=2.9 \mathrm{~Hz}), 132.7(\mathrm{~d}, J=12.1 \mathrm{~Hz}), 131.3,129.7(\mathrm{~d}, J=13.8$ $\mathrm{Hz}), 129.5,128.4,126.4,126.4,125.4,122.6,122.2,121.5,57.2,24.6,17.6,17.4,14.9$. The $\mathrm{C}$-ipso atom of $\mathrm{B}\left(\mathrm{C}_{6} \mathrm{~F}_{5}\right)_{4}{ }^{-}$are not observed due to considerable broadening while coupling with the quadrupolar boron nuclei. ${ }^{29} \mathrm{Si}$ INEPT NMR $(60 \mathrm{MHz}, d-\mathrm{o}-$ Dichlorobenzene) $\delta 25.51(\mathrm{~d}, J=19.4 \mathrm{~Hz}) .{ }^{15} \mathrm{~N}\left({ }^{1} \mathrm{H}-{ }^{15} \mathrm{~N}\right.$ HMBC) NMR (41 MHz, $d$-o-Dichlorobenzene) $\delta 304.1 .{ }^{11} \mathrm{~B}\{1 \mathrm{H}\}$ NMR (96 MHz, $d$-o-Dichlorobenzene) $\delta-16.2 .{ }^{19} \mathrm{~F}\{1 \mathrm{H}\}$ NMR (470 MHz, $d$-o-Dichlorobenzene) $\delta-132.6--133.2(\mathrm{~m}, 8 \mathrm{~F}),-$ $163.5(\mathrm{t}, \mathrm{J}=20.4 \mathrm{~Hz}, 4 \mathrm{~F}),-167.3(\mathrm{t}, J=19.3 \mathrm{~Hz}, 8 \mathrm{~F}) .{ }^{31} \mathrm{P}$ NMR (122 MHz, $d$-o-Dichlorobenzene) $\delta 52.7$.

General procedure for the reduction of phosphine oxides. In a glovebox under argon atmosphere, a solution of $\mathrm{Ph}_{3} \mathrm{C}^{+}\left[\mathrm{B}\left(\mathrm{C}_{6} \mathrm{~F}_{5}\right)_{4}\right]^{-}(16.6 \mathrm{mg}, 0.018 \mathrm{mmol}, 0.05$ eq. $)$ in $\mathrm{d}_{8}$-toluene $(0.3 \mathrm{~mL})$, was added to the dry phosphine oxide $(0.36 \mathrm{mmol}$, 1.0 eq.) and then injected into a dry J-Young NMR tube. Deuterated solvent $(0.4 \mathrm{~mL})$ was used to wash the vials and complete the tube at room temperature. Then $\mathrm{PhSiH}_{3}(0.09 \mathrm{~mL}, 0.72 \mathrm{mmol}, 2.0$ eq.) (2.0 eq./P=O function in the molecule) was added into the tube at room temperature. The tube was tightly closed, shaken, and transferred to an oil bath pre-heated at $80^{\circ} \mathrm{C}$ and the reaction monitored through ${ }^{31} \mathrm{P}$ NMR analysis. The reaction was carefully quenched with 1:1 $\mathrm{MeOH} / \mathrm{Et}_{3} \mathrm{~N} \mathrm{mixture} \mathrm{(1} \mathrm{mL)}$ [Caution: exothermic reaction with gas release]. The resulting mixture was concentrated under reduced pressure. The residue was purified by flash chromatography on silica gel with petroleum ether/ethyl acetate as eluent to give pure phosphine. In selected cases the purification is performed through recrystallization in hot methanol or by filtration.

General procedure for the formation of phosphine-borane adducts. For very sensitive phosphines, the above procedure was followed, until complete conversion monitored by ${ }^{31} \mathrm{P}$ NMR. The reaction mixture was then put back into the glovebox and $\mathrm{BH}_{3}$. THF $(1 \mathrm{~mL})$ added dropwise. After $12 \mathrm{~h}$ at room temperature, ${ }^{31} \mathrm{P}$ NMR analysis was performed and showed complete formation of the phosphine-borane adduct. The reaction mixture was then carefully poured onto silica gel into an Erlenmeyer inside the glovebox. The flask was washed with toluene. The reaction mixture was filtered through a Buchner funnel outside glovebox and then washed with EtOAc and concentrated under reduced pressure. The residue was purified by flash chromatography on silica gel with petroleum ether/ethyl acetate as eluent to give the pure phosphine-borane adduct. 


\section{References}

[1] a) S. Fletcher, Org. Chem. Front., 2015, 2, 739-752; b) V. S. C. de Andrade, M. C. S. de Mattos, Curr. Org. Synth., 2015, 12, 309-327; c) B. E. Maryanoff, A. B. Reitz, Chem. Rev., 1989, 89, 863-927.

[2] a) P. C. J. Kamer, P. W. N. M. van Leeuwen, Phosphorus(III) Ligands in Homogeneous Catalysis: Design and Synthesis, John Wiley \& Sons Ltd, 2012; b) D. W. Allen, in Organophosphorus Chemistry, (Ed. J. C. Tebby), Royal Society of Chemistry, Cambridge, 2010, vol. 39, pp. 1-48.

[3] a) J. L. Methot, W. R. Roush, Adv. Synth. Catal., 2004, 346, 1035-1050; b ) Y. Wei, M. Shi, Acc. Chem. Res., 2010, 43, 1005-1018; c) A. Marinetti, Synlett, 2010, 174-194; d) H. Ni, W.-L. Chan, Y. Lu, Chem. Rev., 2018, 118, 9344-9411; e) H. Guo, Y. C. Fan, Z; Sun, Y. Wu, O. Kwon, Chem. Rev., 2018, 118, 10049-10293; f) J. M. Lipshultz, G. Li, A. T. Radosevich, J. Am. Chem. Soc., 2021, 143, 1699-1721.

[4] a) M. Eggersdorfer, D. Laudert, U. Letinois, T. McClymont, J. Medlock, T. Netscher, W. Bonrath, Angew. Chem. Int. Ed., 2012, 51, 12960-12990; Angew. Chem., 2012, 124, 13134-13165; b) K. C. Kumara Swamy, N. N. Bhuvan Kumar, E. Balaraman, K. V. P. Pavan Kumar, Chem. Rev., 2009, 109, 2551-2651; c) R. Appel, Angew. Chem. Int. Ed. Engl., 1975, 14, 801-811; Angew. Chem., 1975, 87, 863-874.

[5] a) J. H. Clark, T. J. Farmer, L. Herrero-Davila, J. Sherwood, Green Chem., 2016, 18, 3914-3934; b) P. T. Anastas, J. C. Warner in Green Chemistry: Theory and Practice, Oxford University Press, New York, 1998.

[6] Y. Li, L.-Q. Lu, S. Das, S. Pisiewicz, K. Junge, M. Beller, J. Am. Chem. Soc., 2012, 134, 18325-18329.

[7] For reviews, see: a) D. Hérault, D. H. Nguyen, D. Nuel, G. Buono, Chem. Soc. Rev., 2015, 44, 2508-2528; b) T. Kovacs, G. Keglevich, Curr. Org. Chem., 2017, 21, 569-585.

[8] a) T. Imamoto, T. Oshiki, T. Onozawa, T. Kusumoto, K. Sato, J. Am. Chem. Soc., 1990, 112, 5244-5252; b) S. Yang, X. Han, M. Luo, J. Gao, W. Chu, Y. Ding, Russ. J. Gen. Chem., 2015, 85, 1156-1160.

[9] a) R. Köster, Y. Morita, Angew. Chem., 1965, 77, 589-590; b) M. Kwiatkowska, G. Krasiński, M. Cypryk, T. Cierpiał, P. Kiełbasiński, Tetrahedron: Asymmetry, 2011, 22, 1581-1590.

[10] F. Mathey, R. Maillet, Tetrahedron Lett., 1980, 21, 2525-2526.

[11] H. Fritzsche, U. Hasserodt, F. Korte, G. Friese, K. Adrian, H. J. Arenz, Chem. Ber., 1964, 97, $1988-1993$.

[12] M. Zablocka, B. Delest, A. Igau, A. Skowronska, J.-P. Majoral, Tetrahedron Lett., 1997, 38, 5997-6000.

[13] Y. Handa, J. Inanaga, M. Yamaguchi, J. Chem. Soc., Chem. Commun., 1989, 298-299.

[14] L. Horner, W. D. Balzer, Tetrahedron Lett., 1965, 6, 1157-1162.

[15] H. Fritzsche, U. Hasserodt, F. Korte, G. Friese, K. Adrian, Chem. Ber., 1965, 98, 171-174.

[16] M. Berthod, A. Favre-Réguillon, J. Mohamad, G. Mignani, G. Docherty, M. Lemaire, Synlett, 2007, $1545-1548$.

[17] T. Coumbe, N. J. Lawrence, F. Muhammad, Tetrahedron Lett., 1994, 35, 625-628.

[18] L. Pehlivan, E. Métay, D. Delbrayelle, G. Mignani, M. Lemaire, Tetrahedron, 2012, 68, 3151-3155.

[19] Y. Li, S. Das, S. Zhou, K. Junge, M. Beller, J. Am. Chem. Soc., 2012, 134, 9727-9732.

[20] M. Mehta, I. Garcia de la Arada, M. Perez, D. Porwal, M. Oestreich, D. W. Stephan, Organometallics, 2016, 35, 10301035.

[21] Y. Li, L.-Q. Lu, S. Das, S. Pisiewicz, K. Junge, M. Beller, J. Am. Chem. Soc., 2012, 134, 18325-18329.

[22] M.-L. Schirmer, S. Jopp, J. Holz, A. Spannenberg, T. Werner, Adv. Synth. Catal., 2016, 358, $26-29$.

[23] A. Chardon, O. Maubert, J. Rouden, J. Blanchet, ChemCatChem, 2017, 9, 4460-4464.

[24] P. Ducos, V. Liautard, F. Robert, Y. Landais, Chem. Eur. J., 2015, 21, 11573-11578; b) A. Fernandes, C. Laye, S. Pramanik, D. Palmeira, O. Ömür Pekel, S. Massip, M. Schmidtmann, T. Müller, F. Robert, Y. Landais, J. Am. Chem. Soc., 2020, 142, 564-572.

[25] a) V. R. Naidu, S. Ni, J. Franzen, ChemCatChem, 2015, 7, 1896-1905 and references cited therein; b) J. Bah, J. Franzen, Chem. Eur. J., 2014, 20, 1066-1072.

[26] a) E.Y.-X. Chen, T. J. Marks, Chem. Rev., 2000, 100, 1391-1434; b) I. Krossing, I. Raabe, Angew. Chem. Int. Ed., 2004, 43, 2066-2090; Angew. Chem., 2004, 116, 2116-2142.

[27] C. Douvris, O. V. Ozerov, Science, 2008, 321, 1188-1190.

[28] J. B. Lambert, Y. Zhao, H. Wu, J. Org. Chem., 1999, 64, 2729-2736.

[29] Q. Xu, C.-Q. Zhao, L.-B. Han, J. Am. Chem. Soc., 2008, 130, 12648-12655.

[30] G. Baccolini, C. Boga, M. Mazzacurati, F. Sangirardi, Org. Lett., 2006, 8, 1677-1680.

[31] J. Holz, H. Jiao, M. Gandelman, A. Börner, Eur. J. Org. Chem., 2018, 2018, 2984-2994.

[32] a) R. K. Haynes, T.-L. Au-Yeung, W.-K. Chan, W.-L. Lam, Z.-Y. Li, L.-L. Yeung, A. S.-C. Chan, P. Li, M. Koen, C. R. Mitchell, S. C. Vonwiller, Eur. J. Org. Chem., 2000, 2000, 3205-3216; b) G. A. Gray, S. E. Cremer, K. L. Marsi, J. Am. Chem. Soc., 1976, 98, 2109-2118.

[33] M. Segi, Y. Nakamura, T. Nakajima, S. Suga, Chem. Lett., 1983, 12, 913-916.

[34] a) T. Imamoto, T. Kusumoto, N. Suzuki, K. Sato, J. Am. Chem. Soc., 1985, 107, 5301-5303; b) T. Imamoto, K. Hirose, H. Amano, H. Seki, Main Group Chem., 1996, 1, 331-338.

[35] B. D. Vineyard, W. S. Knowles, M. J. Sabacky, G. L. Bachman, D. J. Weinkauff, J. Am. Chem. Soc., 1977, 99, 59465952.

[36] F. O. Stark, J. R. Falender, A. P. Wright, Silicones, Comprehensive Organometallic Chemistry, 1982, Vol. 9.3, $305-363$.

[37] K. L. Marsi, J. Org. Chem., 1974, 39, 265-267.

[38] J. Y. Corey, J. Am. Chem. Soc., 1975, 97, 3237-3238.

[39] O. M. Demchuk, R. Jasiński, K. M. Pietrusiewicz, Heteroat. Chem., 2015, 26, 441-448. 